\title{
SCREENING FORAGE GRASSES WITH ATOMIC ABSORPTION SPECTROMETRY, X-RAY FLUORESCENCE AND X-RAY MICROANALYSIS
}

\author{
S. Sabreen ${ }^{1}$, S. Saiga ${ }^{2}$ and M.H. Rahman ${ }^{3 *}$ \\ ${ }^{1}$ The United Graduate School of Agricultural Sciences, Iwate University, Morioka 020, Japan \\ ${ }^{2}$ Department of Plant Production, Faculty of Agriculture, Iwate University, \\ Morioka 020, Japan \\ ${ }^{3}$ Department of Soil and Environmental Sciences, University of Barishal \\ Barishal 8254, Bangladesh
}

\begin{abstract}
Breeding cool-season (C3) grasses with higher magnesium (Mg) content is a promising attempt for reducing grass tetany hazard in ruminants. Faster methods for plant mineral analyses could increase the number of individual plants screened for higher $\mathrm{Mg}$ content (High-Mg). This study evaluates the effectiveness of energy dispersive X-ray microanalysis (EDX) as well as energy reflectance X-ray spectrometry (XRF) for screening high-Mg grass genotypes. The approach was verified by using two tall fescue cultivars having known differences in magnesium (Mg) content, viz. HiMag (high-Mg cultivar) and Ky-31 (control cultivar). We assumed that cultivars with known variation in $\mathrm{Mg}$ concentrations could provide a test for the applicability of the new methodology in finding naturally occurring high and low Mg containing grass genotypes. Plants samples included a population of 8 plants consisting of four harvests for three years and were analyzed for $\mathrm{Mg}$, calcium $(\mathrm{Ca})$, and potassium $(\mathrm{K})$ by EDX and ERF, and data were verified with atomic absorption spectrometry wet (AAS). While observing the frequency distribution for different nutrient concentrations, HiMag tall fescue showed higher Mg and lower $\mathrm{K}$ concentrations than that of $\mathrm{Ky}-31$. There was positive linear relationship between AAS and EDX estimated $\mathrm{Mg}, \mathrm{Ca}$ and $\mathrm{K}(r=0.88$, 0.62 and 0.89 , respectively), indicating close agreement between AAS and EDX estimation. Also, there was a positive linear relationship between AAS and XRF, as the $r$ values were $0.87,0.65$ and 0.88 for $\mathrm{Mg}$, $\mathrm{Ca}$, and $\mathrm{K}$, respectively. The tetany ration was established for EDX and $\mathrm{XRF}$ and the results were dependable with wet chemistry.
\end{abstract}

Keywords: High-Mg $\mathrm{C}_{3}$ grasses, Mineral, Screening, Grass Tetany Index

\footnotetext{
*Corresponding Author: mhrahman1997@yahoo.co.nz
} 


\section{INTRODUCTION}

Throughout the world, grass tetany causes economic losses from death or reduced performance of livestock. Grass tetany triggered by nutritional imbalances and related with available $\mathrm{K}, \mathrm{Ca}$ and $\mathrm{Mg}$ concentration in forages (Kemp and $\mathrm{t}^{\prime}$ Hart, 1957). Attempts to reduce or eliminate the incidence of grass tetany have been focused on selective breeding of forages for higher levels of $\mathrm{Mg}$ and lower tetany potential (Asay et al., 2001). As a consequence, Magnet Italian ryegrass, Mgwell orchardgrass, and HiMag tall fescue were bred as the high-Mg cultivars of Italian ryegrass, orchardgrass and tall fescue, respectively (Hides and Thomas, 1981; Saiga et al., 2002; Mayland and Sleper, 1993). There is a continued need to breed high-Mg cultivars since the malady of grass tetany causes considerable economic loss in agriculture. Forage breeding programs for improving mineral concentrations are labor and time intensive. More efficient methods for plant analyses for minerals e.g., potassium $(\mathrm{K})$, calcium $(\mathrm{Ca})$ and magnesium $(\mathrm{Mg})$ associated with grass tetany are necessary. Mineral element analyses by conventional methods (e.g. Titrimetric, Flame photometric, Spectrophotometric, AAS) are costly, laborious and time consuming. If faster methods of mineral analyses could be introduced, family selections by forage breeders could be speeded up and the number of individuals screened could be increased (Sleper, 1979).

Atomic absorption spectrometry is a standard and most popular technique for measuring plant nutrients. However, energy dispersive X-ray microanalyzer (EDX) analysis is a rapid method for measuring the chemical composition of plants using ashed samples. Recent research has used EDX for mineral analysis in ashed plant samples (Hodson and Sangster, 2002). Also, applicability of X-ray microanalysis (EDX) to screen orchardgrass individuals for $\mathrm{Mg}$ at the seedling stage has been suggested (Saiga et al., 2002). X-ray microanalysis can give the relative density of the selected mineral elements in ashed plant samples (Saiga and Izumi, 1997; Saiga et al., 1997), and thus the values could be used as general guideline for screening. Apart from this, energy reflectance X-ray spectrometry (XRF) data represent the actual mineral element concentration, but with easy sample preparation (Hutton and Norrish, 1977; Norrish and Hutton, 1977). On the other hand, AAS (wet chemistry), a widely used standard method for mineral analysis is expensive, time consuming, laborious and requires lots of attentions. This suggests that EDX and XRF should be efficient method for screening high-Mg genotype. Making comparisons of the EDX and XRF analysis data with AAS can confirm the use of these two methods for the screening of high-Mg plants. In the present study, efficacy of both the methods for mineral analyses was verified by using known high-Mg cultivar of tall fescue (Festuca arundinacea Schreb.), named as HiMag comparing with a control tall fescue cultivar Kentucky 31 (Ky-31). Apparently, the differences between these two tall fescue cultivars exists in their Mg content and this will emphasize the suitability 
of $\mathrm{EDX}$ and $\mathrm{XRF}$ for determining forage $\mathrm{Mg}$ content. In addition to $\mathrm{Mg}$ concentrations of $\mathrm{Ca}$ and $\mathrm{K}$ were also measured as those elements are responsible for tetany risk in ruminant.

\section{MATERIALS AND METHODS}

\section{Plant materials and growth conditions}

Two tall fescue (Festuca arundinacea Schreb.) cultivars consisting high-Mg and control cultivars namely, HiMag and Kentucky 31 (Ky-31), respectively, were used in this study. Germinated seeds of the cultivars were grown in small plastic box containing vermiculite for 70 days in a controlled environment of phytotron. The air temperature of the phytotron was maintained at $25^{\circ} \mathrm{C}$ day $/ 15^{\circ} \mathrm{C}$ night, and the photoperiod was maintained at $14 \mathrm{~h}$. Relative humidity was approximately $75 \%$ and the light intensity was $280-\mu \mathrm{mol}$ photons $\mathrm{m}^{-2} \mathrm{~s}^{-1}$. Fifty seedlings of similar growth from each cultivar were transplanted in the experimental field (Uedai: Upper grassland: $\left.39^{\circ} 41^{\prime} 59.81 " \mathrm{~N} ; 141^{\circ} 09^{\prime} 0.04^{\prime \prime E}\right)$ in Morioka of Iwate University, Morioka, Japan, in a distance of 30 by $40 \mathrm{~cm}$ to an area of $6 \mathrm{~m}^{2}$. The soil was characterized as Umbric Andosol, pH 6.0, with exchangeable cations: $\mathrm{K}^{+}, 1.22 \mathrm{cmol}_{\mathrm{c}} / \mathrm{kg} ; \mathrm{Ca}^{2+} 22.10$ $\mathrm{cmol}_{\mathrm{c}} / \mathrm{kg}$; and $\mathrm{Mg}^{2+} 4.37 \mathrm{cmol}_{\mathrm{c}} / \mathrm{kg}$.

\section{Plant sampling and field management}

Eight plants from each cultivar were randomly selected for analysis and considered as experimental unit for four harvests. Plants were sampled (6 cm cutting height) at four sampling date of May 28 (Cut 1), June 16 (Cut 2); August 4 (Cut 3) and November 6 (Cut 4), while sampling height of the plants were in the range of 50-60 $\mathrm{cm}$ and the plants were in vegetative stage without any heading. After collecting sample, leftover plants in the field were harvested and thrown away. Then dolomite (one metric ton/ha), nitrogen $(140 \mathrm{~kg} / \mathrm{ha}), \mathrm{P}_{2} \mathrm{O}_{5}(280 \mathrm{~kg} / \mathrm{ha})$ and $\mathrm{K}_{2} \mathrm{O}(140 \mathrm{~kg} / \mathrm{ha})$ were applied to the field and left for regrowth for next sampling. Samples from different year (3yrs) and seasons (4 cuts/harvests) were collected to have much environmental influence in the mineral nutrient content of plant population.

\section{Nutrient analyses of plant samples}

Plant samples were dried at $70^{\circ} \mathrm{C}$ for 48 hours, and ground to pass a $1 \mathrm{~mm}$ screen with a cyclone mill. This sample was used for determining $\mathrm{Mg}, \mathrm{Ca}$, and $\mathrm{K}$ by the three methods. A subsample of dried plant $(0.5 \mathrm{~g})$ was digested with nitric-perchloric (2:1) acid mixture (Jackson, 1973) and concentrations of magnesium (Mg), calcium $(\mathrm{Ca})$, and potassium $(\mathrm{K})$ in the solutions were analyzed by the Atomic Absorption Spectrophotometer (Perkin Elmer 3300). Each sample was replicated three times and the results were expressed as concentration (\% DM) of each cultivar. Dried plant subsamples $(1.0 \mathrm{~g})$ were ashed in crucibles at $600^{\circ} \mathrm{C}$ for 3 hours. Mineral density in the ashed shoot was determined by the energy dispersive X-ray (EDX) analyzer 
(JED-2140) attached with scanning electron microscope (JSM-5800LV) as described by Saiga and Izumi (1997) to investigate the mineral density in plants. The EDX analyzer was used in the scanning mode with the following conditions: raster size $1 \times 1 \mathrm{~cm}^{2}$ at $\times 90$ magnification; emission current, $79 \mu \AA$; accelerating voltage, $15 \mathrm{kV}$; specimen working distance, $10 \mathrm{~mm}$; tilt angle of $35^{\circ}$; detector to specimen distance, $40 \mathrm{~mm}$; and live time, 100s. Each sample was replicated three times by the EDX analyzer. The results obtained from EDX analyzer were converted to weight $\%$ basis.

Each plant subsample of 0.5 to $1.0 \mathrm{~g}$ was pressed (with a coherent disc of $2.5 \mathrm{~cm}$ ) by using 15 tons of pressure to form a pellet with a uniform surface (Rahman and Saiga, 2007a). Experience has shown that some samples give trouble due to swelling if allowed to take up moisture from the air. The pellets should therefore be stored in a desiccator or prepared using plant powder which has been allowed to come to equilibrium with the atmosphere (Rahman and Saiga, 2007b). Magnesium, Ca, and K contents of both sides of the pellet were measured with a live time of 100s by energy reflectance X-ray fluorescence (XRF) spectrometry (JEOL Co., JSX-3200, Element Analyzer) as described by Hutton and Norrish (1977) and Norrish and Hutton (977). Each plant sample was replicated two times and the results were calculated as dry matter percentage $(\% \mathrm{DM})$. The results were presented with an average of four harvests.

\section{Calculation and statistical analysis}

Grass tetany (GT) index was calculated according to Kemp and 't Hart (1957) based on average data obtained from three methods. Data for mineral element concentrations (as determined by three analytical methods) were used in developing multiple regression equations and calculating standard deviation (SD) and coefficient of variance (CV) by Microsoft Excel. The Tukey test was performed for comparison of means (SAS Institute, Cary, NC, USA). Average data for 3 years and 4 cuts with 8 plants were employed in this study.

\section{RESULTS AND DISCUSSION}

Frequency distribution of $\mathrm{Mg}, \mathrm{Ca}$ and $\mathrm{K}$ concentrations as determined by wet chemistry of eight tall fescue samples were presented in Fig 1. We assumed that cultivars with known variation in $\mathrm{Mg}$ concentrations could provide a test for the applicability of the new methodology in finding naturally occurring high and low $\mathrm{Mg}$ containing grass genotypes. Magnesium concentrations of HiMag tall fescue ranged from 0.30 to $0.54 \% \mathrm{DM}$, while that of $\mathrm{Ky}-31$ ranged from 0.15 to $0.30 \% \mathrm{DM}$. Calcium concentrations among the populations did not vary distinctly. In the case of $\mathrm{K}$ concentrations, the opposite trend to $\mathrm{Mg}$ concentrations was observed. The $\mathrm{K}$ concentrations of HiMag tall fescue were lower than that of Ky-31. Potassium concentrations of HiMag tall fescue ranged from 1.3 to 2.5\% DM while that of Ky-31 ranged from 2.9 to $4.4 \%$. Potassium concentrations in a large number of plants were 
distributed from 1.6 to $2.2 \%$ DM for HiMag while that of Ky-31 was from 3.5 to $3.8 \% \mathrm{DM}$. These results were in correspondence with previous findings (Wilkinson and Mayland, 1997; Sabreen et al., 2003; Sabreen and Saiga, 2004; Sabreen et al., 2004).
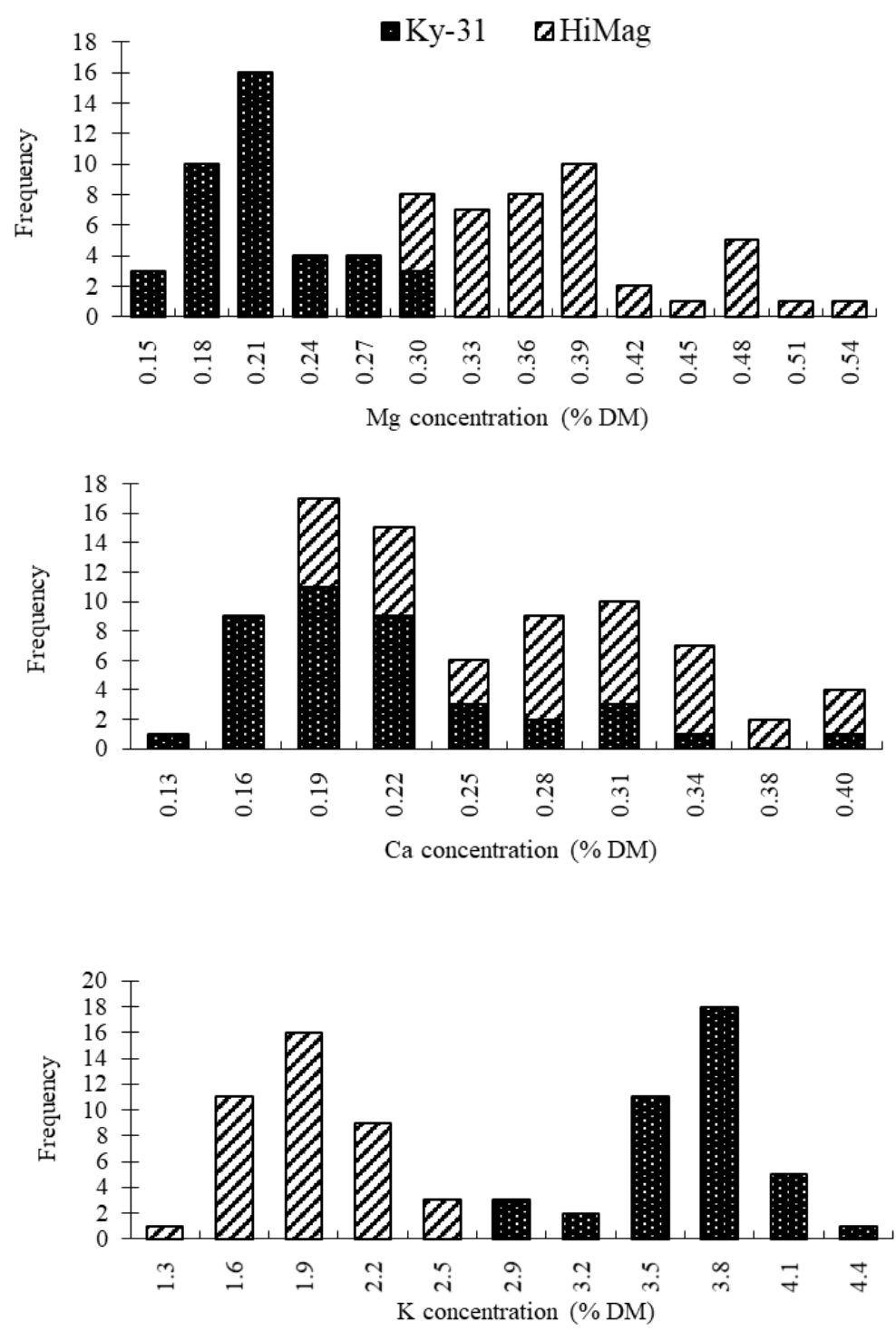

Figure 1. Frequency distribution for $\mathrm{Mg}, \mathrm{Ca}$, and $\mathrm{K}$ concentrations of eighty plants of two tall fescue cultivars as determined by wet chemistry. 
The known high-Mg cultivar HiMag tall fescue was compared with Ky-31 to test the effectiveness of EDX and XRF analysis for screening high-Mg genotypes. Considering wet chemistry as a standard method both EDX and XRF analysis data were verified. Statistical data and equation calibration statistics for elemental concentrations determined by various analytical methods were shown in Table 1 .

Table 1. Statistical data $(\mathrm{n}=96)$ for $\mathrm{Mg}, \mathrm{Ca}$ and $\mathrm{K}$ concentrations $(\% \mathrm{DM})$ of two tall fescue cultivars as determined by AAS, EDX and XRF.

\begin{tabular}{|c|c|c|c|c|c|c|}
\hline Element & Analytical method & Forage & Range & Mean & $\mathrm{SD}^{1}$ & $\mathrm{CV}(\%)^{2}$ \\
\hline \multirow[t]{6}{*}{$\mathrm{Mg}$} & \multirow[t]{2}{*}{ Wet chemistry } & High-Mg & $0.165-0.540$ & 0.306 & 0.10 & 32.66 \\
\hline & & Ку-31 & $0.211-0.641$ & 0.341 & 0.11 & 35.56 \\
\hline & \multirow[t]{2}{*}{ EDX } & High-Mg & $0.261-1.258$ & 0.591 & 0.26 & 40.58 \\
\hline & & $\mathrm{Ky}-31$ & $0.299-1.321$ & 0.348 & 0.29 & 41.24 \\
\hline & \multirow[t]{2}{*}{ XRF } & High-Mg & $0.145-0.697$ & 0.298 & 0.14 & 38.48 \\
\hline & & Ку-31 & $0.154-0.769$ & 0.435 & 0.15 & 36.01 \\
\hline \multirow[t]{6}{*}{$\mathrm{Ca}$} & \multirow[t]{2}{*}{ Wet chemistry } & High-Mg & $0.144-0.421$ & 0.264 & 0.07 & 26.50 \\
\hline & & Ку-31 & $0.154-0.434$ & 0.275 & 0.10 & 28.32 \\
\hline & \multirow[t]{2}{*}{ EDX } & High-Mg & $0.703-1.335$ & 0.929 & 0.16 & 17.23 \\
\hline & & Ку-31 & $0.777-1.446$ & 0.909 & 0.14 & 15.21 \\
\hline & \multirow[t]{2}{*}{ XRF } & High-Mg & $0.218-0.649$ & 0.369 & 0.10 & 25.16 \\
\hline & & Ку-31 & $0.245-0.687$ & 0.341 & 0.12 & 26.24 \\
\hline \multirow[t]{6}{*}{$\mathrm{K}$} & \multirow[t]{2}{*}{ Wet chemistry } & High-Mg & $1.347-4.472$ & 2.880 & 0.92 & 31.94 \\
\hline & & Ку-31 & $1.457-4.997$ & 3.714 & 0.99 & 32.24 \\
\hline & \multirow[t]{2}{*}{ EDX } & High-Mg & $3.057-7.057$ & 6.884 & 1.07 & 21.91 \\
\hline & & Ку-31 & $3.554-7.152$ & 6.485 & 1.12 & 22.14 \\
\hline & \multirow[t]{2}{*}{ XRF } & High-Mg & $1.559-5.289$ & 3.166 & 0.97 & 30.64 \\
\hline & & Ку-31 & $1.614-5.352$ & 4.655 & 0.98 & 31.21 \\
\hline
\end{tabular}

${ }^{1}$ Standard deviation; ${ }^{2}$ Coefficient of variance.

Magnesium concentrations for high $\mathrm{Mg}$ fodder as determined by wet chemistry ranged from 0.165 to $0.540 \% \mathrm{DM}$ (average $0.306 \% \mathrm{DM}$ ). Corresponding values for $\mathrm{Ca}$ and $\mathrm{K}$ were 0.144 to $0.421 \% \mathrm{DM}$ (average $0.264 \% \mathrm{DM}$ ), and 1.347 to $4.472 \%$ $\mathrm{DM}$ (average $2.880 \% \mathrm{DM}$ ). The corresponding $\mathrm{EDX}$ data for $\mathrm{Mg}, \mathrm{Ca}$ and $\mathrm{K}$ concentrations were $0.591,0.929$ and 6.884 weight $\%$, respectively. On the other hand, the corresponding XRF values for average $\mathrm{Mg}, \mathrm{Ca}$ and $\mathrm{K}$ concentrations were 0.298, 0.369 and $3.166 \% \mathrm{DM}$, respectively. Means and standard deviations are listed to show the concentration level and variation among analytical methods. 

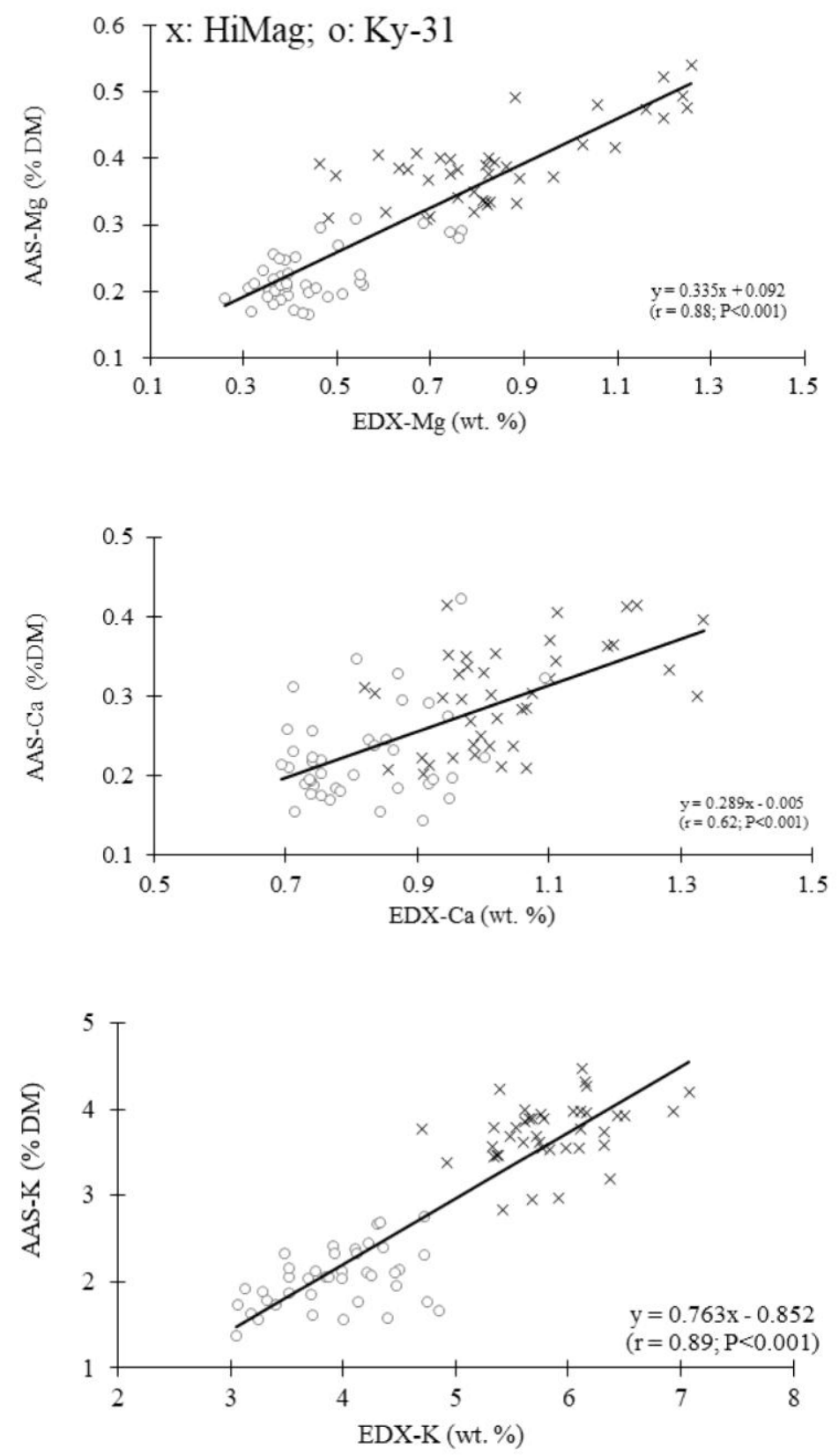

Figure 2. Relationship between wet chemistry estimated $\mathrm{Mg}, \mathrm{Ca}$ and $\mathrm{K}$ concentrations and EDX estimated $\mathrm{Mg}, \mathrm{Ca}$ and $\mathrm{K}$ content for eight plants of two tall fescue cultivars 
X-ray microanalysis allows the use of small amounts of plant sample without the destruction of the whole plant. Efficient use of X-ray microanalysis for screening high-Mg plants can shortened the time consumed for mineral analysis for improving mineral concentrations of forage plants. The relationship between wet chemistry and EDX estimated $\mathrm{Mg}, \mathrm{Ca}$ and $\mathrm{K}$ concentrations were shown in Fig. 2. Correlation coefficients for $\mathrm{Mg}, \mathrm{Ca}$, and $\mathrm{K}$ were $\mathrm{r}=0.88,0.62$, and 0.89 , respectively. This indicates the positive linear relationship between wet chemistry and EDX estimated $\mathrm{Mg}, \mathrm{Ca}$ and $\mathrm{K}$. Thus, close agreement between wet chemistry and EDX estimation is apparent. Apart from this, the slope for $\mathrm{Mg}$ and $\mathrm{Ca}$ was deviated from one, even though that of $\mathrm{K}$ was close to one. The result suggests that by using the regression equations for $\mathrm{Mg}, \mathrm{Ca}$ and $\mathrm{K}$ effective screening for high-Mg plants can be done, as the $\mathrm{r}$ values were high.

The EDX estimated $\mathrm{Mg}, \mathrm{Ca}$ and $\mathrm{K}$ is an indication of the proportion of these three mineral elements responsible for grass tetany. If the balance among these three elements is disturbed forage has increased possibility of causing grass tetany (Sleper et al., 1989). This emphasizes the importance of determining the proportion of these elements while screening high-Mg plants. The coefficient of variance inferred that even though EDX cannot estimate the exact mineral concentration this method is efficient enough to screen high-Mg genotypes if the difference within the population for $\mathrm{Mg}$ is large (Table 1).

The relationship between wet chemistry and XRF estimated $\mathrm{Mg}, \mathrm{Ca}$ and $\mathrm{K}$ was shown in Fig. 3. There was a positive linear relationship between wet chemistry and $\mathrm{ERF}$, and the correlation coefficient (r) values were $0.87,0.65$ and 0.88 for $\mathrm{Mg}, \mathrm{Ca}$, and $\mathrm{K}$, respectively. A good calibration equation should result in a slope very close to 1.0 , and this is the case for $\mathrm{Ca}$ (slope $=0.88$ ) and $\mathrm{K}$ (slope $=0.92$ ), while $\mathrm{Mg}$ had a slope of 0.60 . These data indicate that the equations for $\mathrm{Ca}$ and $\mathrm{K}$ had accuracy (low bias) and precision and provided good estimates of validation samples (slope near 1.0). However, the slope for $\mathrm{Mg}$ was deviated from one, the intercept is near zero. This may have been due to the distinct variation for $\mathrm{Mg}$ concentration between high-Mg (HiMag) and control (Ky-31) cultivar of tall fescue. High correlation coefficient value for $\mathrm{Mg}$ is $(\mathrm{r}=0.87)$ indicates the applicability of XRF analysis for screening high-Mg plants. The efficiency and dependability of X-ray fluorescence (XRF) spectroscopy to analyze macro- and micronutrients in pea (Pisum sativum L.) seeds were performed by Bamrah et al. (2019). They observed that the $\mathrm{R}^{2}$ value was more than 0.85 for all studied elements except $\mathrm{K}(0.54)$. Based on the results they conferred that the using XRF for elements analysis is compatible with AAS method. 


\section{x: HiMag; o: Ky-31}
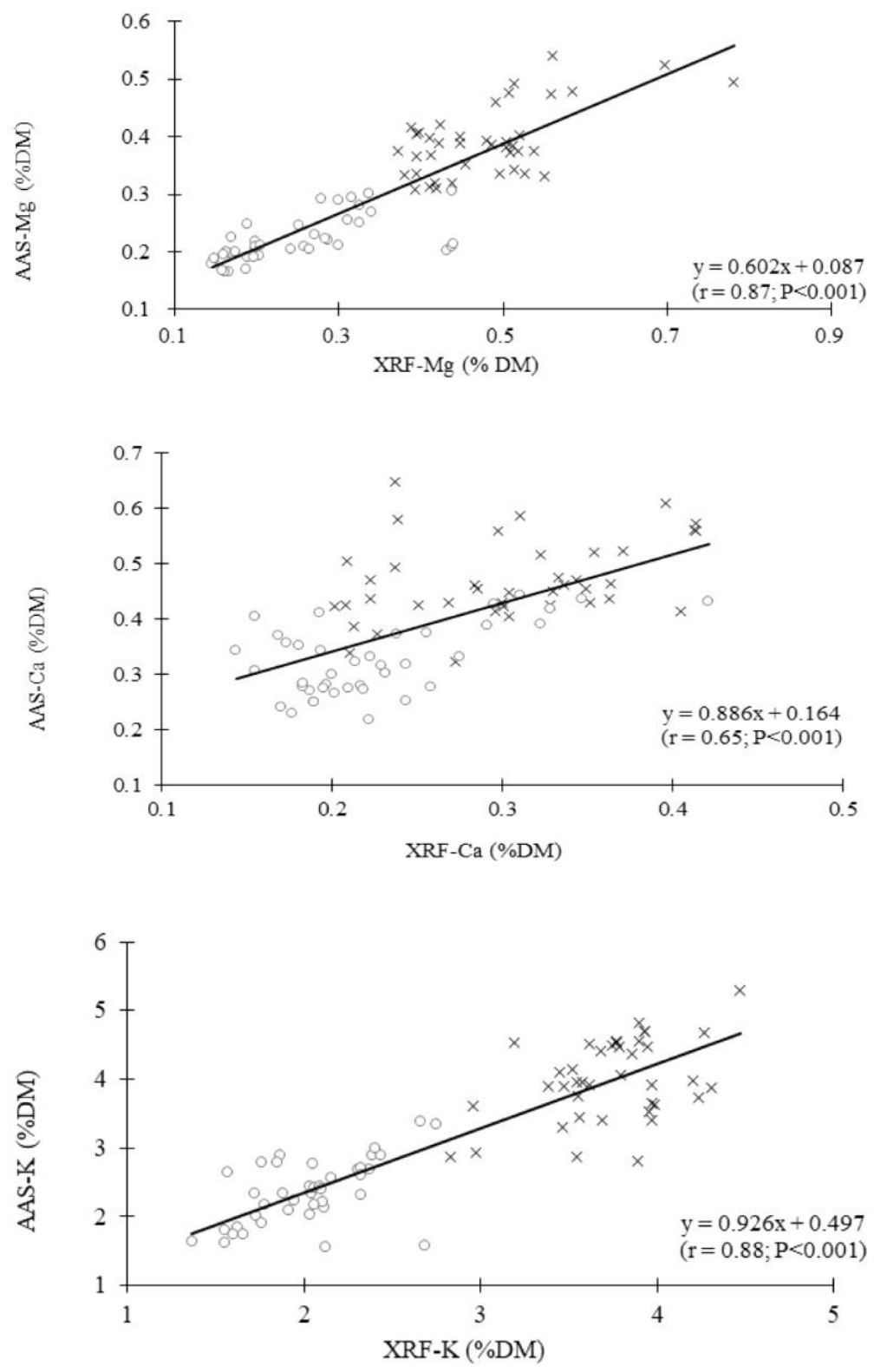

Figure 3. Relationship between wet chemistry estimated $\mathrm{Mg}, \mathrm{Ca}$ and $\mathrm{K}$ concentrations and ERF estimated $\mathrm{Ma}, \mathrm{Ca}$ and $\mathrm{K}$ content for eight plants for two tall fescue cultivars 
The grass tetany (GT) index calculation was done as GT $=\mathrm{K} / \mathrm{Ca}+\mathrm{Mg}$ (Table 2) with average data for four cuts of eight plant for each cultivar reared for three years. The highest values for GT index were observed for AAS methods, followed by XRF and the lowest GT index were recorded for EDX. Irrespective of methods higher grass tetany index was recorded in Ky-31 compared to High-Mg cultivar.

Table 2. Grass tetany index of two tall fescue cultivars ${ }^{1}$

\begin{tabular}{ccccc}
\hline Analytical method & Forage & K/Ca+Mg & SD $^{2}$ & CV, $\%^{3}$ \\
\hline AAS & High-Mg & 1.91 & 0.25 & 11.87 \\
& Ky-31 & 2.26 & & \\
EDX & High-Mg & 1.85 & 0.27 & 13.17 \\
& Ky-31 & 2.23 & & \\
XRF & High-Mg & 1.88 & 0.25 & 12.36 \\
& Ky-31 & 2.24 & & \\
AAS & High-Mg & 1.91 & 0.03 & 1.60 \\
EDX & High-Mg & 1.85 & & \\
XRF & High-Mg & 1.88 & & \\
AAS & Ky-31 & 2.26 & 0.68 & \\
EDX & Ky-31 & 2.23 & & \\
XRF & Ky-31 & 2.24 & & \\
\hline
\end{tabular}

${ }^{1}$ Average of eight plants for 4 cuts with 3 growing seasons;

${ }^{2}$ Standard deviation; ${ }^{3}$ Coefficient of variance.

The ranges of variation of values of the coefficient of variation (CV) differ among the different methods (Table 1) for nutrients and their ratios (Table 2). Irrespective of grass cultivars $\mathrm{CV}$ for $\mathrm{Mg}, \mathrm{Ca}$ and $\mathrm{K}$ measured by different methods can be arranged as $\mathrm{EDX}>\mathrm{XRF}>\mathrm{AAS}, \mathrm{AAS}>\mathrm{XRF}>\mathrm{EDX}$ and $\mathrm{AAS} \geq \mathrm{XRF}>\mathrm{EDX}$, respectively (Table 1). Regardless of grass cultivars the values of CV tetany index were arranged as EDX> XRF> AAS whereas irrespective of methods the value of $\mathrm{CV}$ can be arranged as High-Mg> Ky-31 (Table 2). The values of $\mathrm{CV}$ for $\mathrm{Mg}, \mathrm{Ca}$ and $\mathrm{K}$ were higher than their ratio, $\mathrm{K} / \mathrm{Ca}+\mathrm{Mg}$. The coefficient of variations for nutrient ratio were $1.6 \%$ and $0.68 \%$ for High- $\mathrm{Mg}$ and $\mathrm{Ky}-31$, respectively, for different methods (Table 2).

The coefficient of variation $(\mathrm{CV})$ is close to zero suggests that there is a high precision of the sample's central tendency, i.e., the variability of the parameters 
measured by different methods is very low. Even though the results from EDX and/or XRF were well suited with AAS method, nevertheless, it could be recommended that the more replications are required in the nutrients analysis with EDX and/or XRF which will give reasonably concord results with AAS.

\section{CONCLUSION}

For EDX analyzer the advantage is that less skill is required to ash and analyze the samples without destroying the whole plant. Additionally, XRF has advantage of requiring less time and expertise to grind and analyze the sample. Apart from this, mineral analyses by wet chemistry can be time consuming and expensive. Also, wet chemical analysis for a large number of samples can be tedious, thus increasing error in mineral analyses data. When samples are included in the calibration equations from years and population varied in mineral concentrations, the calibration was precise enough to screen high-Mg plants of tall fescue. Therefore, this study offers the promise of a rapid and relatively inexpensive means of screening forage plants for higher $\mathrm{Mg}$ content by using EDX and XRF. The next step in evaluating these techniques is to use samples, which include several high-Mg cultivars from various species.

\section{ACKNOWLEDGEMENT}

Authors are very grateful to Dr. M J Hodson (Oxford Brookes University, Headington, UK) for his valuable comments and critical reading of the manuscript. Thanks are extended to Dr. H F Mayland (USDA-ARS, Kimberly, Idaho, USA) for his kind cooperation and valuable suggestions during conducting the experiment.

\section{REFERENCES}

Asay, K.H., Mayland, H.F., Jefferson, P.G., Berdahl, J.D., Karn, J.F. and Waldron. B.L. (2001). Parent-progeny relationships and genotype $\mathrm{x}$ environment effects for factors associated with grass tetany and forage quality in Russian wildrye. Crop Science, 41: 1478-1484.

Bamrah, R.K., Vijayan, P., Karunakaran, C., Muir, D., Hallin, E., Stobbs, J., Goetz, B., Nickerson, M., Tanino, K. and Warkentin T.D. (2019). Evaluation of x-ray fluorescence spectroscopy as a tool for nutrient analysis of pea seeds. Crop Science, 59: 2689-2700.

Hides, D.H. and Thomas, T.A. (1981). Variation in the magnesium content of grasses and its improvement by selection. Journal of Science, Food and Agriculture, 32: 990-991.

Hodson, M.J. and Sangster, A.G. (2002). X-ray microanalytical studies of mineral localization in the needles of white pine (Pinus strobes L.). Annals Botany, 89: 367-374.

Hutton, J.T. and Norrish, K. (1977). Plant analyses by x-ray spectrometry. II Elements of atomic number greater than 20. X-ray Spectrometry, 6: 12-17.

Jackson, M.L. (1973). Soil Chemical Analysis. Prentice Hall of India Pvt. Ltd., New Delhi.

Kemp, A. and 't Hart, M. L. (1957). Grass tetany in grazing milking cows. Netherlands Journal of Agricultural Science, 5: 4-17. 
Mayland, H.F. and Sleper, D.A. (1993). Developing a tall fescue for reduced grass tetany risk. Proceedings International Grassland Congress, Palmerston North, New Zealand and Australia 17: 1095-1096.

Norrish, K. and Hutton, J.T. (1977). Plant analyses by x-ray spectrometry. I. Low atomic number elements, sodium to calcium. X-ray Spectrometry, 6: 6-11.

Rahman, M.H. and Saiga, S. (2007a). The use of slurry for managing forage mixtures in temperate brown forest soils. Journal of Applied Sciences, 7: 687-694.

Rahman, M.H. and Saiga, S. (2007b). Genetic variability in tetany potentiality of orchard grass as influenced by application of dairy manure and chemical fertilizer. International Journal of Soil Science, 2(1): 29-39.

Sabreen, S., Saiga, S., Saitoh, H., Tsuiki, M. and Mayland, H.F. (2003). Performance of high-Mg cultivars of three cool-season grasses in nutrient solution culture. Journal of Plant Nutrition, 28: 589-605.

Sabreen, S. and Saiga, S. (2004). Potassium level suitable for screening high magnesium containing grass seedlings under solution culture. Journal of Plant Nutrition, 27: 1015-1027

Sabreen, S., Saiga, S. and Tsuiki, M. (2004). X-ray microanalysis of high-Mg cultivars of three cool-season grasses grown hydroponically with different potassium treatments. Grassland Science, 49: 581-586.

Saiga, S. and Izumi, K. (1997). Comparison of X-ray microanalysis methods in screening mineral concentration for orchardgrass (Dactylis glomerata L.) plants. Grassland Science, 43: 18-23.

Saiga, S., Saitoh, H., Sabreen, S. and Tsuiki, M. (2002). Effectiveness of nutrient solution culture for detecting genetic variability in $\mathrm{Mg}$ concentration of orchard grass (Dactylis glomerata L.) Grassland Science, 48: 209-215.

Saiga, S., Nishimura, Y. and Izumi, K. (1997). Application of X-ray microanalysis to evaluate mineral concentrations of different organs and growths in orchard grass (Dactylis glomerata L.). Grassland Science, 43: 111-116.

Sleper, D.A. (1979). Plant breeding, selection and species in relation to grass tetany. In: Grass Tetany. ASA Special Publication No. 35. ASA, CSA, and SSSA, Inc., WI, USA. pp. 63-77.

Sleper, D.A., Vogel, K.P., Asay, K.H. and Mayland, H.F. (1989). Using plant breeding and genetics to overcome the incidence of grass tetany. Journal of Animal Sciences, 67: 3456-3462.

Wilkinson, S.R. and Mayland, H.F. (1997). Yield and mineral concentration of HiMag compared to other tall fescue cultivars grown in the southern piedmont. Journal of Plant Nutrition, 20: 1317-1331. 